\title{
Radiofrequency Thermal Ablation in Painful Myeloma of the Clavicle
}

\begin{abstract}
Department of Anesthesiology and Pain Medicine, Amirmomenin Hospital, Tehran Azad Islamic University of Medical Science,
*Anesthesiology and Pain Department, ${ }^{\dagger}$ Hematology and Oncology Department, Rasoul-Akram Hospital, Tehran University of Medical Sciences, Tehran, Iran
\end{abstract}

Helen Gharaei, Farnad Imani*, and Masoud Vakily ${ }^{\dagger}$

A 57-year-old male patient had myeloma. He had severe pain in the left clavicle that did not respond to radiotherapy; therefore, it was treated with radiofrequency thermal ablation (RFTA). Under fluoroscopic guidance, two RF needles at a distance of $1.5 \mathrm{~cm}$ from each other were inserted into the mass and conventional radiofrequency $\left(90^{\circ} \mathrm{C}\right.$ and 60 seconds) at two different depths $(1 \mathrm{~cm}$ apart) was applied. Then, $2 \mathrm{ml}$ of $0.5 \%$ ropivacaine along with triamcinolone $40 \mathrm{mg}$ was injected in each needle. The visual analogue pain score (VAS from 0 to 10) was decreased from 8 to 0 . In the next 3 months of follow-up, the patient was very satisfied with the procedure and the mass gradually became smaller. There were no complications. This study shows that RFTA could be a useful method for pain management in painful osteolytic myeloma lesions in the clavicle (Korean J Pain 2014; 27: 72-76)

\section{Key Words:}

clavicle, myeloma, radiofrequency thermal ablation.

Myeloma can be diagnosed by the neoplastic proliferation of a plasma cell clone which results in extensive osteolysis, bone pain and fracture. In 2/3 of the cases, pain can be detected in the back, chest and less often in the limbs. The affected bone is tender also [1]. A myeloma lesion is along with tumor cell proliferation, osteoclast activation that destroys the bone structure and osteoblast suppression which builds new bones. This lesion has a lytic nature and it is unlikely along with new bone formation. Localized bone formation in the skull, clavicle and sternum can be so much expanded that they could be palpated [2].
Cancer patients usually suffer more than one kind of pain. This pain can be constant or intermittent or perhaps an acute pain superimposed on chronic background pain. This pain can be due to the illness or the treatment. Tumor expansion puts pressure on the surrounding organs causing pain. Psychological factors like depression and anxiety can affect the comprehension of the pain and its intensity. Usual treatments are local treatments (radiotherapy and surgery), systematic treatments (chemotherapy, hormone therapy, bisphosphonates, and radiopharmaceuticals) and analgesic drugs (opioid and Nonsteroidal Antiinflammatory

Received September 13, 2013. Revised November 18, 2013. Accepted November 18, 2013.

Correspondence to: Helen Gharaei

Department of Anesthesiology and Pain Medicine, Boali Hospital, Emam-Hosaein Sq, Damavand St, Tehran, Iran

Tel: +98-2133348036, Fax: +98-2166515758, E-mail: helengharaee@yahoo.com

(c) This is an open-access article distributed under the terms of the Creative Commons Attribution Non-Commercial License (http:// creativecommons.org/licenses/by-nc/3.0/), which permits unrestricted non-commercial use, distribution, and reproduction in any medium, provided the original work is properly cited.

Copyright (c) The Korean Pain Society, 2014 
Drugs (NSAIDs). It can be treated by radiotherapy, but it is not effective in pain management in $20-30 \%$ of cases. On one hand, a patient that has gone under radiotherapy and still complains of pain cannot go under radiotherapy again because of a limitation in normal tissue tolerance $[3,4]$. In addition, it takes $12-20$ weeks to see the maximum result of radiotherapy, while the radiofrequency effect is much faster $[5,6]$.

The patient that has not responded to these usual treatments has limited choices in pain management. Patients who cannot receive surgery or chemotherapy or radiotherapy need alternative treatment options. Radiofrequency is a palliative treatment that can improve life quality with less morbidity [7]. Ablation due to high and alternating frequency current is applied with a needle electrode, which causes frictional heat and necrosis, and has been used in primary tumors and metastasis [8]. We present a case that shows the analgesic efficacy of RFTA in a painful osteolytic myeloma lesion in the clavicle.

\section{CASE REPORT}

The patient was a 57-year-old man with a history of coming into contact with chemical gases during the war of 1981. He was referred to the emergency room (ER) with an acute abdomen and hemorrhage about 6 years ago. At that time, the diagnosis was acute renal failure and myeloma. The patient's blood abnormality was treated very

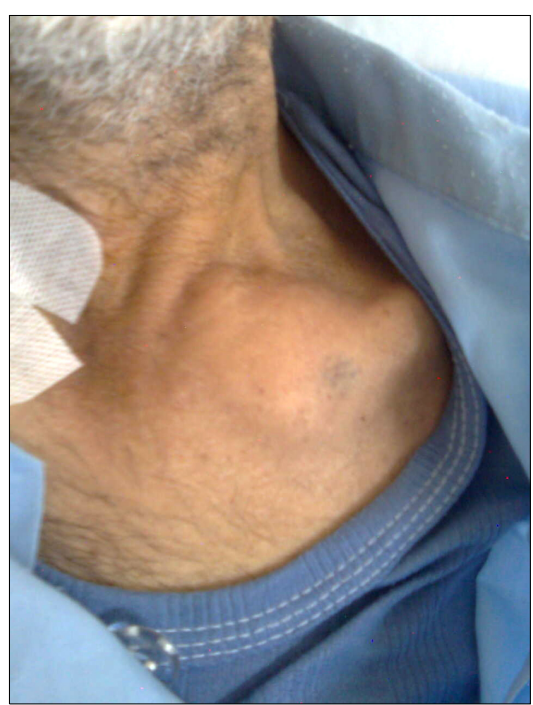

Fig. 1. Left clavicular mass. well in the hematology department and he went under dialysis. He did not come back to the hematology department for myeloma maintenance therapy until four months ago when he came to the ER with hoarseness, tenderness in a hind limb, bone pains, movement limitation in the forelimbs with severe pain (VAS 6) in the left clavicle. He underwent 10 sessions of clavicle radiotherapy before admission to the pain clinic. His clavicular pain did not respond to radiotherapy and opioids.

In the physical examination, the patient complained of generalized bone pain especially in left clavicle. There was a $5 \times 7 \mathrm{~cm}$ mass in $1 / 3$ of the internal part of the clavicle (Fig. 1). There was no redness or edema and the mass was fixed to the bone and in pain on palpation. It was a new localized, deep, uncomfortable pain in the left clavicle.

Both shoulders and arms were tender with movement limitation. Bilateral limited elbow extension and flexion deformity were seen. Hind limbs force was decreased (2 from 5). There was no sensory deficit. In the shoulder examination, there was no hypertrophy, heat, erythema and tenderness. Clavicle conventional radiofrequency was chosen as a treatment. The patient's blood test and coagulation test were normal (platelet counts $=7,400$ per microliter). In the plain radiography other than widespread lytic myeloma lesions especially in the shoulders and arms, there was a big lesion in the left clavicle which was also detected in the chest X-ray and chest CT scan (Fig. 2).

After IV sedation (midazolam $1 \mathrm{mg}$ and fentanyl 50

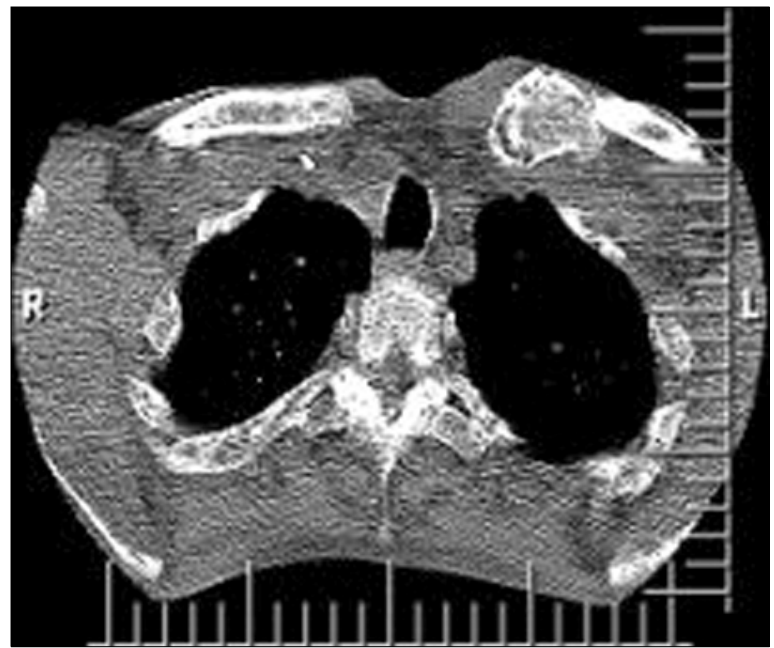

Fig. 2. CT-scans of the chest and osteolytic clavicular mass on the left. 
mg), prep \& drape were done in the supine position. The clavicular mass was antisepticised and the anesthetic was lidocaine 1\%. Two radiofrequency needles (OWL, Diros Technology Inc., Ontario, Canada. sharp, 20 gauge, 100 $\mathrm{mm}$, active tip $10 \mathrm{~mm}$ ), $1.5 \mathrm{~cm}$ from each other were inserted into the mass. Under the guide of the fluoroscopy, the needles were inserted into the middle part of the mass and during the pass, the needles were aspirated for any

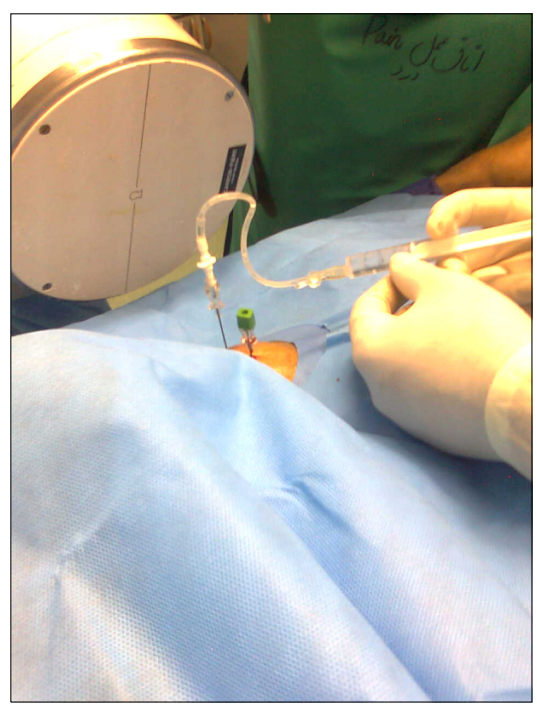

Fig. 3. Radiofrequency needles in the clavicle.

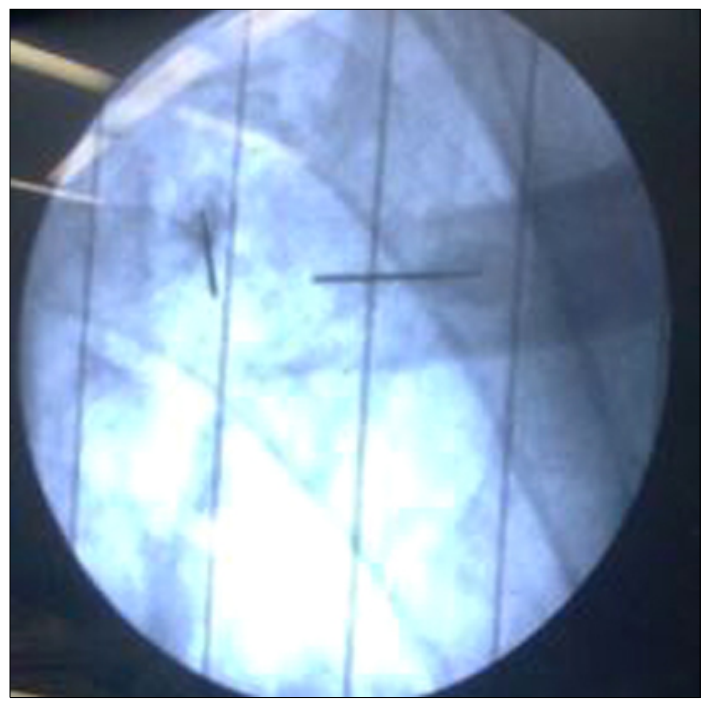

Fig. 4. Anterior-posterior fluoroscopic view of the needles in the clavicle. possibility of blood. And then, after passing the bone and feeling a sense of pop in the non-ionic water, $3 \mathrm{ml}$ of soluble contrast media (Iodixanol 320) were injected and its distribution was seen directly and the contours of mass were clear. The patient informed us of any shooting pain in the upper extremity during the procedure. After placing the pads on the patient's arm, the stylet was pulled out and the radiofrequency probe was inserted. Then, two times a radiofrequency current at $90^{\circ} \mathrm{C}$ was applied for 60 seconds at the two points $1 \mathrm{~cm}$ apart from each other. After that, $2 \mathrm{ml}$ of $0.5 \%$ ropivacaine along with triamcinolone 40 $\mathrm{mg}$ were injected in each needle and then the needle and the probe were pulled out together (Fig. 3-5). The procedure went very smoothly without any pain or need for more analgesic injection. In the recovery room, VAS dropped to zero and movement of the hands improved. He could move his shoulder and arms more comfortably. There was no hematoma or sensory and motor deficits or any kind of radiating pain in the extremity. The visual analogue pain score (VAS from 0 to 10 ) decreased from 8 to 0 . In the next 3 months of follow-up, the patient was very satisfied with the procedure and there was no pain at the clavicular site and did not need any analgesic for it. The mass gradually became smaller. There were no complications. He did not suffer from any pain at the clavicular site until he died after 3 months.

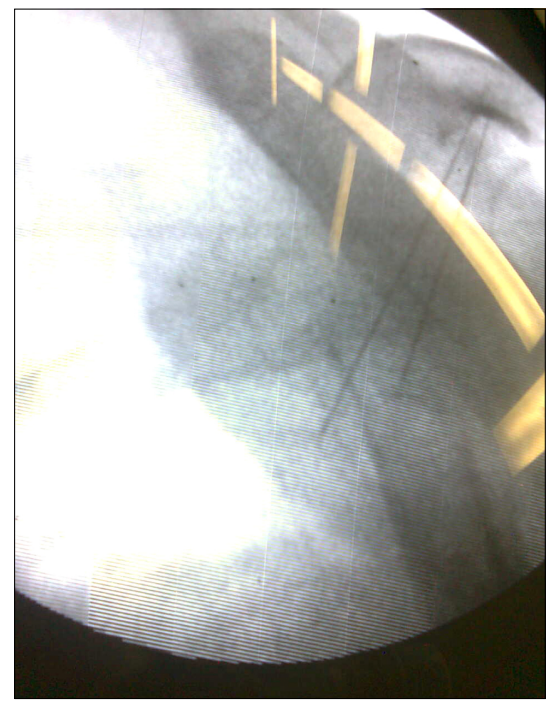

Fig. 5. Lateral oblique fluoroscopic view of needles in the clavicle. 


\section{DISCUSSION}

Our patient with painful myeloma of the clavicle responded very well to conventional radiofrequency and his pain was completely gone. The use of radiofrequency current at $90^{\circ} \mathrm{C}$ for 60 seconds had very good result in managing painful myeloma of the clavicle. We used an instrument that is for neuroablation and available in most pain clinics. Using this instrument allows more people to benefit from radiofrequency in the future.

The pathophysiology of cancer pain is a local or systemic inflammatory response by producing pro-inflammatory cytokines that facilitates pain transmission. Invasion of cancer cells to mechanically sensitive tissues (e.g. visceral pain) or the entrapment and injury of nerves (e.g. neuropathic pain) causes pain.

After pain generation, there is central sensitization and chronic pain. Tumors have immune system cells, which by releasing factors like endothelin, prostaglandin and tumor necrosis factor alpha (TNF- $\alpha$ ), that cause the stimulation or sensitivity of afferent nerves. Tumors also release some proteins which through acidosis cause local pain. Proteolytic enzymes and sensory and sympathetic nerve injury result in neuropathic pain. Nerve infiltration of sensitive bone marrow causes pain, osteolysis and fracture of abnormal bone structure. Stimulation of the sensitive afferent nerves in the bone cortex and the surrounding tissues can also be a reason for pain [9-13].

High frequency current can manage this pain. A high alternating frequency current enters the applicator. Its result is ion movement in the tissue producing heat and destroying the surrounding tissue and tumor. This severe heat destroys tumor cells, decreases cytokines and tumor factors involved in both nerve sensitization and osteoclast activity. In addition, stopping the tumor growth into the periosteum and surrounding tissue manages the pain and decreases microfractures $[8,14,15]$.

Radiofrequency can be used in patients with moderate to severe pain (4 to 10). The pain must be limited to one or two sites and confirmed by cross-sectional imaging. The lesion has to have an osteolytic or combined osteolytic and osteoblastic nature or be composed of soft tissue [14,15].

Dupuy reported on the use of radiofrequency in metastatic bone pain management which was confirmed by other studies [16]. The primary and secondary success rates were $87 \%$ and $83 \%$. Surgery had the same success but with multiple complications. On the other hand, radiofrequency costs much less. In addition, it is the gold standard treatment for osteoid osteomas $[16,17]$. The success rate of radiofrequency in the liver, kidney, lungs and bone tumor ranges from 70-95\% depending on the tumor location and nature. Radiofrequency is a safe non-invasive method. The radiofrequency probe is usually placed into the tumor with the help of ultrasonography, CT, MRI or fluoroscopes. Controlling the ablation procedure depends on the instrument. Usually, impedance depending systems are used. Radiofrequency does not have major contraindication and can easily be repeated or mixed with other treatments [18].

Other benign conditions (chondroblastoma, osteoblastoma, giant cell tumor, etc.) can also be treated by this technique. Today, we are witnessing an improvement in minimally invasive therapies like chemoablation, thermoablation, percutaneous grafting, acetabuloplasty and osteoblast skin grafts and vertebroplasty. Microwave, radiofrequency, ultrasound or high frequency laser is used and ablation happens at over $60^{\circ} \mathrm{C}$ so that tumor cells die. Usually a radiofrequency below $30 \mathrm{MHz}$ is used and most of the instruments are around $500-375 \mathrm{KHz}$. Ablation can occur through cryotherapy with necrosis occurring below 20 degrees [19].

In a study by Aono and coworkers, cooled RF Radiofrequency was effective in managing intractable pain due to bone metastasis in 9 metastasis cancer patients (metastasis to the femur, vertebrae column, pelvis, scapula and Humerus) with no possibility of surgery and in patients that did not respond to radiotherapy and opioid treatments [20].

Goetz and coworkers reported 43 patients with painful osteolytic bone metastasis who were treated with image-guided radiofrequency ablation using multiple needles [18]. The primary pain score was 4 out of 10 and the patients did not respond to radiotherapy or opioids or were suitable candidates for these kinds of treatments. The pain score dropped from 7.9 to $4.5,3$ and 1.4. Pain management was $95 \%$ successful and opioid consumption decreased in weeks 8 and 12. Radiofrequency in the pain management of bone cancer is a cheap, effective method with few complications.

Conventional radiofrequency use in myeloma of the clavicle and its perfect response showed that conventional radiofrequency could be an effective method in managing painful osteolytic myeloma lesions. More use of this meth- 
od in the future and gathering more information can introduce this method as a terminal method for managing painful bony metastatic lesions.

\section{REFERENCES}

1. Rajkumar SV. Plasma cell disorders. In: Goldman's cecil medicine. 24th ed. Edited by Goldman L, Schafer Al. Philadelphia (PA), Elsevier Saunders. 2012, pp 1237-40.

2. Munshi NC, Longo DL, Anderson KC. Plasma cell disorders. In: Harrison's principle of internal medicine. 18th ed. Edited by Longo DL, Fauci AS, Kasper DL, Hauser SL, Jameson JL, Loscalzo J. New York (NY), McGraw-Hill, Medical. 2012, pp 941-2.

3. Janjan NA. Radiation for bone metastases: conventional techniques and the role of systemic radiopharmaceuticals. Cancer 1997; 80(8 Suppl): 1628-45.

4. Tharmalingam S, Chow E, Harris K, Hird A, Sinclair E. Quality of life measurement in bone metastases: a literature review. J Pain Res 2008; 1: 49-58.

5. Schaefer O, Lohrmann C, Herling M, Uhrmeister P, Langer M. Combined radiofrequency thermal ablation and percutaneous cementoplasty treatment of a pathologic fracture. J Vasc Interv Radiol 2002; 13: 1047-50.

6. Jeremic B, Shibamoto Y, Acimovic L, Milicic B, Milisavljevic $S$, Nikolic $N$, et al. A randomized trial of three single-dose radiation therapy regimens in the treatment of metastatic bone pain. Int J Radiat Oncol Biol Phys 1998; 42: 161-7.

7. Helmberger TK. Radiofrequency ablation. In: Percutaneous tumor ablation in medical radiology. Edited by Vogl TJ, Helmberger TK, Mack MG, Reiser MF. Berlin, Springer. 2008, pp 7-11.

8. de Baere T, Elias D, Dromain C, Din MG, Kuoch V, Ducreux $\mathrm{M}$, et al. Radiofrequency ablation of 100 hepatic metastases with a mean follow-up of more than 1 year. AJR Am J Roentgenol 2000; 175: 1619-25.

9. Oprée A, Kress M. Involvement of the proinflammatory cytokines tumor necrosis factor-alpha, $\Perp \mathrm{L}-1$ beta, and $\mathrm{L}-6$ but not IL-8 in the development of heat hyperalgesia: effects on heat-evoked calcitonin gene-related peptide release from rat skin. J Neurosci 2000; 20: 6289-93.

10. Mantyh PW, Clohisy DR, Koltzenburg M, Hunt SP. Molecular mechanisms of cancer pain. Nat Rev Cancer 2002; 2: 201-9.

11. Caraceni A, Martini C, Zecca E, Portenoy RK, Ashby MA, Hawson G, et al. Breakthrough pain characteristics and syndromes in patients with cancer pain. An international survey. Palliat Med 2004; 18: 177-83.

12. Delaney A, Fleetwood-Walker SM, Colvin LA, Fallon M, Translational medicine: cancer pain mechanisms and management. Br J Anaesth 2008; 101: 87-94.

13. Colvin L, Fallon M. Challenges in cancer pain management--bone pain. Eur J Cancer 2008; 44: 1083-90.

14. Smith HS, Mohsin I. Painful boney metastases. Korean J Pain 2013; 26: 223-41.

15. Callstrom MR, Charboneau JW. Image-guided palliation of painful metastases using percutaneous ablation. Tech Vasc Interv Radiol 2007; 10: 120-31.

16. Dupuy DE, Liu D, Hartfeil D, Hanna L, Blume JD, Ahrar K, et al. Percutaneous radiofrequency ablation of painful osseous metastases: a multicenter American College of Radiology Imaging Network trial. Cancer 2010; 116: 989-97.

17. Simon CJ, Dupuy DE. Percutaneous minimally invasive therapies in the treatment of bone tumors: thermal ablation. Semin Musculoskelet Radiol 2006; 10: 137-44.

18. Goetz MP, Callstrom MR, Charboneau JW, Farrell MA, Maus TP, Welch TJ, et al. Percutaneous image-guided radiofrequency ablation of painful metastases involving bone: a multicenter study. J Clin Oncol 2004; 22: 300-6.

19. Santiago FR, Del Mar Castellano García M, Montes JL, García MR, Fernández JM. Treatment of bone tumours by radiofrequency thermal ablation. Curr Rev Musculoskelet Med 2009; 2: 43-50.

20. Carrafiello G, Laganà D, lanniello A, Nicotera P, Fontana F, Dizonno M, et al. Radiofrequency thermal ablation for pain control in patients with single painful bone metastasis from hepatocellular carcinoma. Eur J Radiol 2009; 71: 363-8. 